\title{
A Proposed Model for Studying Information Technology Governance, Management, and Services of an Enterprise: An Integrated Framework of COBIT 5, ITIL ${ }^{\circledR}$ V3, and BSC
}

\author{
Wilai Sunthonwutinun and Vasin Chooprayoon
}

\begin{abstract}
This study aims to integrate conceptual frameworks of COBIT5, ITIL ${ }^{\circledR} \mathrm{V3}$ and balance score card (BSC) into a new unique model in order to study information technology governance (ITG), information technology management (ITM), and information technology services (ITS). Business perspectives and enterprises' impact factors are applied to the new model. The proposed model shows logical relationship between enterprise backgrounds and ITG/ITM/ITS based-BSC, which influence received benefits, acceptable risks, and used resources of the enterprises.
\end{abstract}

Index Terms-Information technology governance, information technology management, information technology services, BSC, COBIT5, ITIL ®V3.

\section{INTRODUCTION}

Nowadays several enterprises encounter with regulatory issues of Information Technology Governance (ITG), Information Technology Management (ITM) and Information Technology Services Management (ITS) concerning with revenue, acceptable risks, and use of enterprise resources. Studying the issues requires a conceptual framework which should be composed of main duties, responsibilities, and ITG/ITM/ITS processes of the enterprises. The framework varies regarding needs of enterprise stakeholders, goals, and objectives.

The popular standard frameworks for studying ITG/ITM/ITS are COBIT5 and ITIL ${ }^{\circledR}$ V3. Based on a recent study of PricewaterhouseCoopers, fifty CIOs of the enterprises worldwide have accepted the frameworks as a mechanic for running best practices in their organizations. Most CIOs (95\%) have followed guidelines of COBIT $(63 \%)$ and ITIL $(60 \%)$ [1]. Mike [2] pointed out that ITIL was the most popular standard used in hospitals (45\%) and $8 \%$ for COBIT and ISO -17799.

Haining, Shouqian, Yanan and Cheng [3] applied ITIL for their research work called the ITSM Model in a case study of garment industry. They selected some processes of ITIL framework to implement in the industry. The selected processes are incident management, configuration

Manuscript received May 19, 2014; revised February 2, 2015.

Wilai Sunthonwutinun and Vasin Chooprayoon are with the Faculty of Information Technology, Rangsit University, Paholyothin Rd., Muang-ake, Lak-hok, Muang, Pathumthani 12000 Thailand (e-mail: wilai55@rsu.ac.th, vasin@rsu.ac.th). management, release management, and service desk.

Most enterprises have implemented only one standard framework for ITG, ITM, and ITS; however, the enterprises still having some obstacles because only one framework cannot cover all tasks of the enterprises. The obstacle issues are 1) alignment of information technology with corporate strategies; 2) cost of failure projects using information technology; 3) insufficient investment on information technology; 4) insufficient information technology competency of each individual in the enterprises; 5) standard quality requirements of the enterprises on information technology services, consulting, and suppliers/providers; 6) ignorance, avoidance, or delegation to others to make decision on information technology of the chief executive of each enterprise; 7) balancing of enterprise benefits, acceptable risk, and wisely using information technology resources of information technology managers; and 8) criteria for choosing standard framework of the enterprises--benefits, related law and regulations, contractual agreement, policies including information technology audit. The eight obstacles always occur during ITG, ITM and ITS processing. Studying ITG, ITM, and ITS needs more than one framework integrated with business perspectives.

According to COBIT 5 which emphasizes information technology governance and management; ITIL ${ }^{\circledR} \mathrm{V} 3$ which plays major roles on information technology services; and Balance Score Card (BSC) which focuses on four business perspectives: financial, customer, internal business processes, and learning \& growth. It is reasonable to unify COBIT 5, ITIL ${ }^{\circledR} \mathrm{V} 3$, and BSC into a single model in order to increase completion of studying ITG, ITM, and ITG in terms of business perspectives.

This study aims to integrate COBIT 5, ITIL ${ }^{\circledR} \mathrm{V} 3$, and BSC into a new single model for studying ITG, ITM and ITS in business perspectives of business enterprises and propose the new model.

\section{Methodology AND Result OF THE StUdy}

This study is a qualitative research using content analysis method as the following steps:

1) Review related literature on ITG, ITM and ITS processes, business perspectives, and factors influencing ITG, ITM and ITS based on COBIT 5, ITIL $^{\circledR} \mathrm{V} 3$ and BSC.

2) Design and develop recording forms for keeping all result data generating from the analysis in a whole step.

3) Analyze correlation of the factors and business 
perspectives.

4) Compare ITG, ITM, ITS and BSC processes in terms of similar and different points.

5) Analyze and define variables which are able to predict impacts of the factors to ITG, ITM, and ITS of the enterprises.

6) Create and develop a new model based on result data from the analysis.

7) The new model was verified by five experts who have high experiences in ITG, ITM, and ITS; some of them are executives working in big public companies. They proved content and structure validity of the proposed model.

TABLE I: ITG, ITM AND ITS PROCESSES BASED ON COBIT 5 AND ITIL $^{\circledR} \mathrm{V} 3$

\begin{tabular}{|c|c|c|c|}
\hline \multicolumn{2}{|c|}{ COBIT 5} & Code & Process name \\
\hline \multirow{5}{*}{ 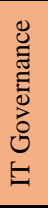 } & \multirow{5}{*}{ 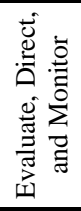 } & EDM01 & $\begin{array}{l}\text { Ensure governance framework setting and } \\
\text { maintenance. }\end{array}$ \\
\hline & & EDM02 & Ensure benefits delivery. \\
\hline & & EDM03 & Ensure risk optimization. \\
\hline & & EDM04 & Ensure resource optimization. \\
\hline & & EDM05 & Ensure stakeholder transparency \\
\hline \multirow{32}{*}{ 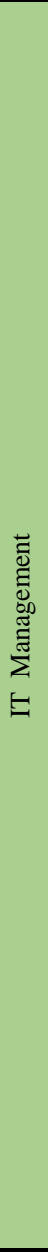 } & \multirow{13}{*}{ 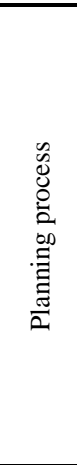 } & AP001 & Manage the IT management framework. \\
\hline & & AP002 & Manage strategy. \\
\hline & & AP003 & Manage enterprise architecture. \\
\hline & & AP004 & Manage innovation. \\
\hline & & AP005 & Manage portfolio. \\
\hline & & AP006 & Manage budget and costs. \\
\hline & & AP007 & Manage human resources. \\
\hline & & AP008 & Manage relationships. \\
\hline & & AP009 & Manage service agreements. \\
\hline & & AP010 & Manage suppliers. \\
\hline & & AP011 & Manage quality. \\
\hline & & AP012 & Manage risk. \\
\hline & & AP013 & Manage security \\
\hline & \multirow{10}{*}{ 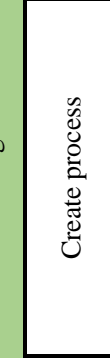 } & BAI01 & Manage programs and projects. \\
\hline & & BAI02 & Manage requirements definition. \\
\hline & & BAI03 & Manage solutions identification and build. \\
\hline & & BAI04 & Manage availability and capacity. \\
\hline & & BAI05 & Manage organizational change enablement. \\
\hline & & BAI06 & Manage changes. \\
\hline & & BAI07 & Manage change acceptance and transitioning. \\
\hline & & BAI08 & Manage knowledge. \\
\hline & & BAI09 & Manage assets. \\
\hline & & BAI10 & Manage configuration. \\
\hline & \multirow{6}{*}{ 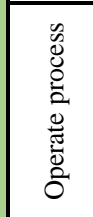 } & DSS01 & Manage operations. \\
\hline & & DSS02 & Manage service requests and incidents. \\
\hline & & DSS03 & Manage problems. \\
\hline & & DSS04 & Manage continuity. \\
\hline & & DSS05 & Manage security services. \\
\hline & & DSS06 & Manage business process controls. \\
\hline & \multirow{3}{*}{ 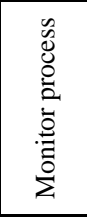 } & MEA01 & $\begin{array}{l}\text { Monitor, evaluate and assess performance and } \\
\text { conformance. }\end{array}$ \\
\hline & & MEA02 & $\begin{array}{l}\text { Monitor, evaluate and assess the system of } \\
\text { internal control. }\end{array}$ \\
\hline & & MEA03 & $\begin{array}{l}\text { Monitor, evaluate and assess compliance with } \\
\text { external requirements }\end{array}$ \\
\hline \multicolumn{4}{|c|}{ ITIL®V3 } \\
\hline \multirow{5}{*}{\multicolumn{2}{|c|}{ 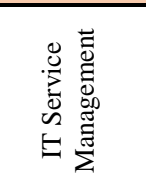 }} & S001 & Service Strategy \\
\hline & & S002 & Service Design \\
\hline & & S003 & Service Transition \\
\hline & & S004 & Service Operation \\
\hline & & S005 & Continual Service Improvement \\
\hline
\end{tabular}

\section{A. Theoritical-Based ITG, ITM, and ITS}

ITG, ITM, and ITS processes are collection of practices influenced by the enterprises' policies and procedure of data manipulation (input and output). ITG is an integration of IT strategies with business processes in order to achieve goals/objectives, and meet requirements of stakeholders of the enterprises, which is composed of evaluation, direction, and monitor. ITM is an IT management regarding governance directions aims to achieve enterprises' objectives. The four processes of ITM are planning, building, running, and monitoring [4], [5]. ITS, a system or a process creating customer satisfactions and good image of enterprises composed of service strategy, design, transition, operation, and continual service improvement [6].

Studying ITG, ITM, and ITS require various standard frameworks, e.g. COBIT 5 and ITIL ${ }^{\circledR}$ V3. The two standards are a major base of this study [4]-[7]. Best practices from the two standards are chosen as shown in Table I.

\section{B. Integration of BSC/COBIT5/ITIL ${ }^{\circledR} V 3$ and \\ ITG/ITM/ITS Process into a Single Model}

A study of PricewaterhouseCoopers [1] pointed-out that most enterprises have adopted and used BSC, COBIT 5, and $\mathrm{ITIL}^{\circledR} \mathrm{V} 3$ for running best practices in their organizations.

Kaplan and Norton [8] introduced BSC in 1992 as a tool for motivating, measuring and evaluating enterprise performance. The four BSC perspectives are financial, customer, internal business processes, and learning \& growth perspectives.

TABLE II: ANALYSIS MATRIC BETWEEN BSC/COBIT5/ ITIL ${ }^{\circledR}$ V3 MODELS AND ITG/ITM/ITS/ BUSINESS PERSPECTIVES

\begin{tabular}{|c|c|c|c|}
\hline \multirow{2}{*}{ Description Processes } & \multicolumn{3}{|c|}{ Standard Framework } \\
\hline & COBIT5 & ITIL ${ }^{\circledR}$ V3 & BSC \\
\hline $\begin{array}{l}\text { 1. Information Technology } \\
\text { Governance -- } 5 \text { processes } \\
\text { (EDM01-EDM05) }\end{array}$ & 5 & $\mathbf{0}$ & $\mathbf{0}$ \\
\hline $\begin{array}{l}\text { 2. Information Technology } \\
\text { Management -- } 32 \text { processes } \\
\text { (AP001-AP013, BA101-BA110, } \\
\text { DSS01-DSS06 and MEA01- } \\
\text { MEA03) }\end{array}$ & 32 & 13 & $\mathbf{0}$ \\
\hline $\begin{array}{l}\text { 3. Information Technology } \\
\text { Management Services -- } 5 \\
\text { processes (S001-S005) }\end{array}$ & $\mathbf{0}$ & 5 & $\mathbf{0}$ \\
\hline $\begin{array}{l}\text { 4. Business Perspective -- } 4 \\
\text { Perspective (P001-P004) }\end{array}$ & $\mathbf{0}$ & $\mathbf{0}$ & 4 \\
\hline
\end{tabular}

COBIT5, a business framework using for maximizing value and minimizing risk of the enterprises. The five COBIT5 principles are 1) meeting requirements of the enterprises' stakeholders, 2) covering end-to-end processes of the enterprises, 3) applying a single integrated framework, 4) enabling a holistic approach, and 5) separating governance from management [4].

ITIL $^{\circledR} \mathrm{V} 3$, a standard framework using for managing ITS based on five principles: 1) service strategy, 2) service design, 3) service transition, 4) service operation, and 5) continual service improvement [6].

This study divided the processes into four perspectives: ITG, ITM, ITS, and business perspectives including different sub-perspectives. The sub-perspectives were analyzed by the COBIT5, ITIL ${ }^{\circledR} \mathrm{V} 3$, and BSC frameworks. The comparison results found that COBIT5 is composed of 5 ITG and 32 ITM processes; 13 ITM and 5 ITS processes 
ITIL $^{\circledR} \mathrm{V} 3$; and 4 BSC perspectives as show in Table II.

The results lead to create the figure of integration of BSC/COBIT5/ ITIL ${ }^{\circledR}$ V3 and ITG/ITM/ITS processes into a single model as shown in Fig. 1.

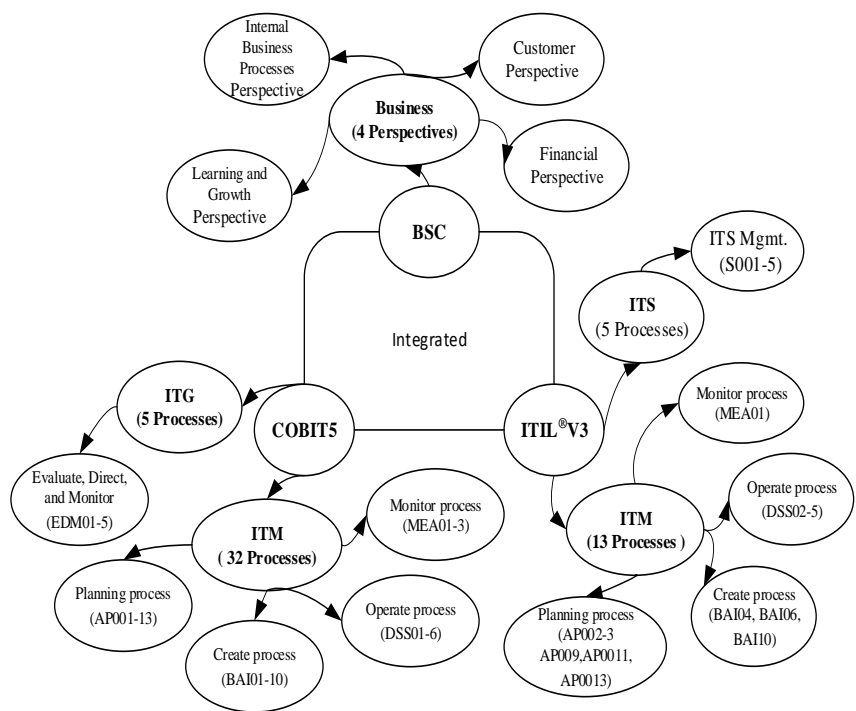

Fig. 1. Integration of BSC/COBIT5/ ITIL ${ }^{\circledR}$ V3 and ITG/ITM/ITS Processes into a Single Model.

\section{Implementation of ITG/ITM/ITS Based on COBIT 5, ITIL ${ }^{\circledR} \mathrm{V} 3$, and BSC}

Many previous research works studying ITG/ITM/ITS based on COBIT 5, ITIL ${ }^{\circledR} \mathrm{V} 3$, and BSC. This study has 13 random sampling articles from the previous research works. The 13 articles were analyzed, the results showed that there were 13 ITG, 27 ITM, 22 ITS processes and 7 BSC perspectives were implemented (see details of the articles in Ref. [2], and [9] to [20]).

\section{Enterprise Backgrounds and Impact Factors}

Studying ITG/ITM/ITS based on COBIT 5/ITIL ${ }^{\circledR} \mathrm{V} 3 /$ $\mathrm{BSC}$ requires some variables to link or predict or discover results from the study. A lot of previous studies used enterprise background in terms of respondents who are main sources of data/information of the study. This study insists on demographic backgrounds of the respondents and propose enterprise financial backgrounds as new variables. The demographic backgrounds of the respondents are gender, age, educational degree, administrative position, revenue and working periods in the enterprise of the respondents including financial status of the enterprises: capital registration, revenue, profit, and total asset [21] as well as three impact factors of the enterprises: Received benefits, acceptable risks, and usable resources used in the study of ITG, ITM, and ITS [4].

\section{E. Propose Model for ITG ITM and ITS}

According to the studying ITG, ITM and ITS integrated with BSC/COBIT5/ITIL ${ }^{\circledR} \mathrm{V} 3$, impact factors and demographic background of the respondents are correlated with all variables as shown in the new model (Fig. 2).

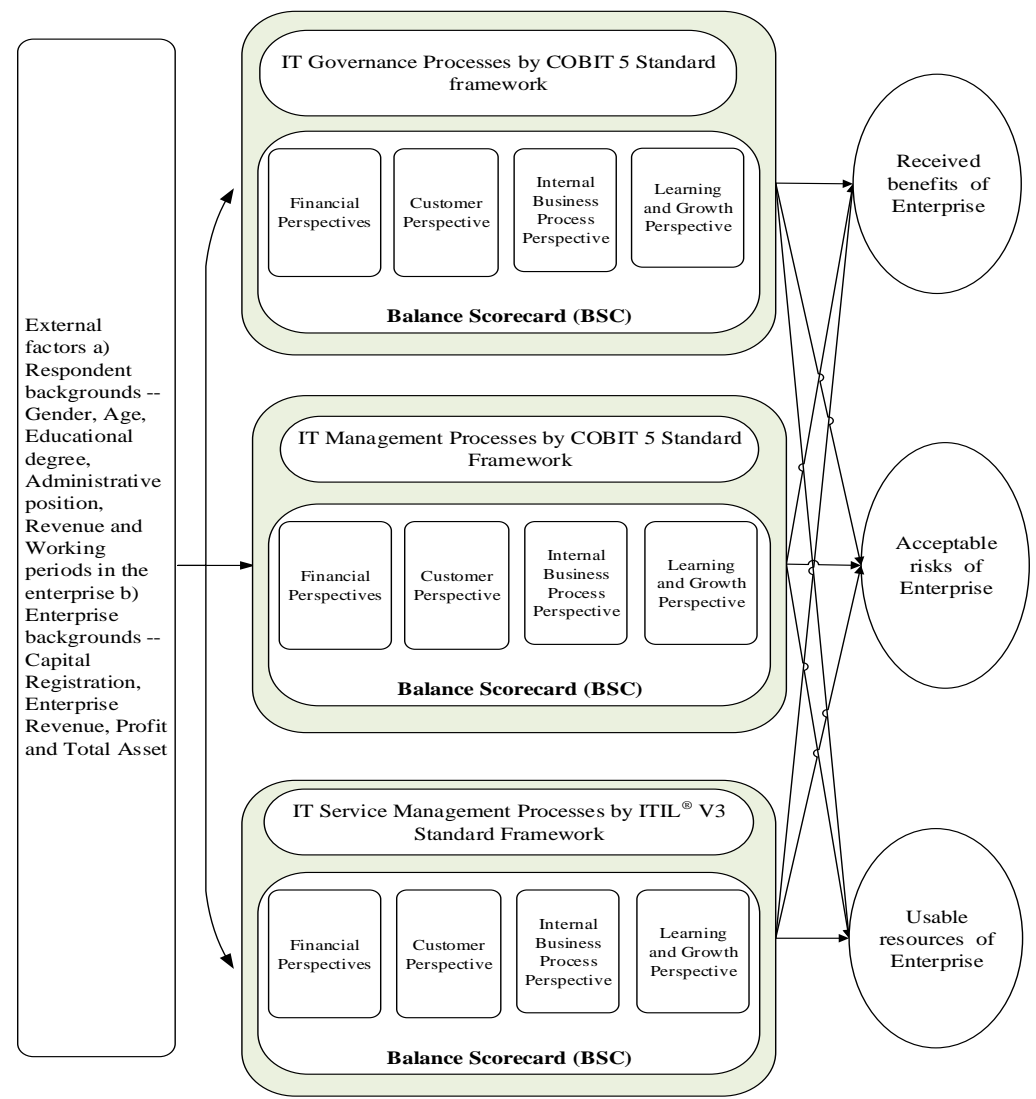

Fig. 2. A proposed model for studying ITG, ITM, ITS.

Fig. 2, a new model for studying ITG, ITM and ITS. The model displays key elements: a) external variables (six respondent backgrounds: sex, age, education, revenue, position and working period as well as four financial status of the enterprises: capital registration, enterprise revenue, profit and total asset); b) ITG and ITM based on COBIT 5 integrated with BSC (four perspectives: finance, customer, internal business process, and learning \& growth); and c) 
ITS based on ITIL $^{\circledR} \mathrm{V} 3$ integrated with BSC (four perspectives). The model also shows that the ITG, ITM and ITS based on BSC will be able to influence the three impact factors of the enterprises: 1) received benefits, 2) acceptable risks, and 3) usable resources. The external factors (background of respondents) and financial status of the enterprises are able to predict influence level of ITG/ITM/ITS based on various perspectives of BSC toward benefits, acceptable risks, and usable resources of the enterprises. The proposed model has already proved by the experts who are CIO from Siam Commercial Bank Public Company Ltd., Petroleum Authority of Thailand (PTT Public Company Ltd.), Quality Assurance Director from Thomson Reuters (Thailand), Chief Executive Auditor Director from The Siam Cement Public Company Ltd., and Former Solution Delivery Director and Quality and Process Improvement Director from. IT One Company Ltd. They pointed out that the model will be able to study ITG, ITM, and ITS properly.

\section{CONCLUSIONS}

Implication of the proposed model is a new research framework for studying information technology governance, management, and services. The model is expected to contribute towards scholarly knowledge in the field. The following contributions will be made. Further study should investigate and categorize additional variables and incorporate them into the model in order to construct a superior embodiment of the direction to study the ITG, ITM, and ITS. This model will lead to wider acceptance of studying ITG, ITM, and ITS in public enterprise. The results will provide better understanding and execution of ITG, ITM, and ITS. Finally, the study will contribute to the appreciation and improved ITG, ITM, and ITS practices for competitiveness related to decision-making on business issues in the enterprises.

In addition, the enterprises would be able to learn what perspectives of ITG/ITM/ITS processes influence their benefits, risks, and use of resources. Organizations should learn and comprehend which is the most important processes necessitate for organization tasks based on which perspectives, correlated variables and its influences in terms of organizational requirements. The study findings would be an approach for developing, organizing, and improving performance efficiency and effectiveness of enterprise staff who involves with the ITG/ITM/ITS under COBIT5 and ITIL ${ }^{\circledR} \mathrm{V} 3$ standard frameworks. Ultimately, the enterprises would be able to apply and utilize the model as a guideline for ITG/ITM/ITS performance matching with their requirements, which will lead to development of their own appropriate standard frameworks.

\section{REFERENCES}

[1] Price water house Coopers. (August 6, 2013). IT governance in practice - Insights from leading CIOs. [Online]. Available: http://www.pwc.com

[2] K. Mike, "Information technology governance, risk and compliance in health care - A management approach," in Proc. International Conference on Developments in e-Systems Engineering, London, UK, 2010, pp. 7-11.

[3] H. Wang; S. Sun, Y. Huang, and S. Cheng, "An ITIL-based IT service management model for garment enterprises," in Proc. 2008
International Conference on Information Management, Innovation Management and Industrial Engineering, Taipei, Taiwan, 2008, pp. 47-51.

[4] ISACA, "Cobit5," Business Framework for the Governance and Management of Enterprise IT. 13, the United States of America, 2013.

[5] CIO. (19 May, 2013). IT governance definition and solutions. [Online]. Available: http://www.cio.com/article/111700/ITGovernanceDefinitionandSoluti ons

[6] ITIL. (August 18, 2013). What is ITIL? [Online]. Available: http://www.itilofficialsite.com/AboutITIL/WhatisITIL.aspx

[7] W. Sunthonwutinun and V. Chooprayoon, "A benchmarking study of standard frameworks for information technology governance," in Proc. Second Asian Conference on Information Systems, Phuket, 2013, p. 2.

[8] R. S. Karplan and D. Norton. (December 13, 2013). Conceptual foundations of the balanced scorecard. [Online]. Available: http://www.hbs.edu/faculty/Publication\%20Files/10074.pdf

[9] A. Bose, A. Heching, and S. Sahu, "A framework for model-based continuous improvement of global IT Service delivery operations," in Proc. 2008 IEEE International Conference on Services Computing, Honolulu, HI, 2008, pp. 197-204.

[10] A. Hochstein, R. Zarnekow, and W. Brenner, "ITIL as common practice reference model for IT service management: formal assessment and implications for practice," in Proc. the 2005 IEEE International Conference on e-Technology, e-Commerce and $e$ Service, 2005, pp. 704-710.

[11] W. Haining, S. Shouqian, H. Yanan, and C. Shiwei, "An ITIL-based IT service management model for garment enterprises," in Proc. 2008 International Conference on Information Management, Innovation Management and Industrial Engineering, Taipei, Taiwan, 2008, pp. 47- 51.

[12] W. Zhen et al., "An ITIL-based IT service management model for chinese universities," in Proc. 5th ACIS International Conference on Software Engineering Research, Management \& Applications, 2007, pp. 493-497.

[13] G. D. Rodosek, "A generic model for IT services and service management," in IFIP/IEEE Eighth International Symposium on Integrated Network Management, 2003, pp. 171-184.

[14] G. Baioco, A. C. M. Costa, C. Z. Calvi, and A. S. Garcia, "IT service management and governance modeling an ITSM configuration process: a foundational ontology approach," in Proc. IFIP/IEEE International Symposium on Integrated Network Management, 2009, pp. 24-33.

[15] M. Salle and G. Di-Vitantonio, "Business service management: The impact of IT governance models on IT management policies," in Proc. IEEE International Conference on Services Computing, 2006, pp. 373-380.

[16] C. Raniery P, D. Santos, W. Cheng, and D. Loewenstern, "Performance management and quantitative modeling of IT service processes using mashup patterns," in Proc. 7th International Conference on Network and Service Management (CNSM), 2011, pp. 1- 9.

[17] H. Yang and Q. Bai, "Research on the IT service cost model," in Proc. 2nd International Conference on Networking and Digital Society, 2010, pp. 241-243

[18] F. J. Meng, X. Y. He, S. X. Yang, and P. Ji, "A unified framework for outsourcing governance," in Proc. the 4th IEEE International Conference on Enterprise Computing, e-Commerce, and e-Services, 2007, pp. 367-374.

[19] A. Wassenaar, "E-governmental value chain models-e-government from a business (modelling) perspective," in Proc. 11th International Workshop on Database and Expert Systems Applications, 2000, pp. 289- 293.

[20] J. Sauve, A. Moura, M. Sampaio, J. Jornada, and E. Radziuk, “An introductory overview and survey of business-driven IT management," in Proc. The First IEEE/IFIP International Workshop on Business-Driven IT Management, 2006, pp. 1-10.

[21] Consumer ethics: An empirical investigation of the ethical beliefs in mainland China, in Proc. 2007 International Conference on Management Science \& Engineering, Harbin, 2007, pp. 1472-1480.

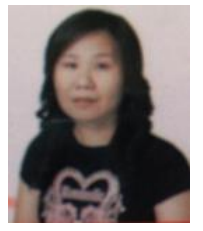

Wilai Sunthonwutinun was born in Thailand on November 5, 1964. She graduated with the master program in computer science from Rangsit University, Pathumthani, Thailand in 1996, and now studying the $\mathrm{Ph} . \mathrm{D}$. program in information technology in Rangsit University.

She has experiences in business sector in Thailand: a) 
Senior Analyst manager at Siam Cement Co., Ltd. (1988-2007), b) Senior Business Director of Xena Technology Co., Ltd. (Jan - June 2008), c) IT audit manager at Pruksa real estate (Public Co.), Ltd. (July 2008-12), and d) SAP consultant freelance (1997-2014).

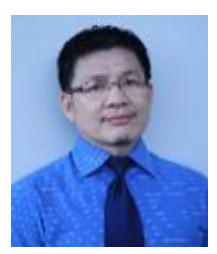

Vasin Chooprayoon was born in Thailand on December 10, 1960. He graduated with the master program in library science and information science from Chulalongkorn University, Bangkok, Thailand in 1988, and graduated with the Ph.D. program in information technology from Murdoch University, Perth, Western Australia, Australia in 2011.

$\mathrm{He}$ is an assistant professor and a principal lecturer working at Faculty of Information Technology, Rangsit University, Thailand. During 2000, he was a visiting research follow conducting his research work in Kyoto University, Japan. In 2004, he was a visiting professor working with several scholars of Vaasa Polytechnic, Finland. He is the founder of bachelor degree program in computer games and multimedia which is the first program in Thailand and he held the first chair of the program. His current position is program chair of the master degree program in information technology management. His updates publications are 1) V. Chooprayoon, "A Study on decision making by Thai software house companies in choosing computer programming languages," in Proc. International Conference on Machine Learning and Cybernetics (ICMLC) Tianjin, China, 2013, and 2) W. Sunthonwutinun and V. Chooprayoon, "A benchmarking study of standard frameworks for information technology governance," in Proc. The Second Asian Conference on Information Systems (ACIS2013), October 31-November 2, 2013, Phuket, Thailand. In 2014 , he received the most outstanding and prestigious lecturer award from Rangsit University, Thailand. 